\title{
The effects of performing squats on an inclined board on thigh muscle activation
}

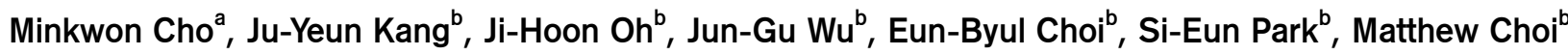 \\ ${ }^{a}$ Department of Physical Therapy, Kaiser Rehabilitation Hospital, Guri, Republic of Korea \\ ${ }^{b}$ Department of Physical Therapy, College of Health Science and Social Welfare, Sahmyook University, Seoul, Republic of Korea
}

\begin{abstract}
Objective: The purpose of this study is to show the effectiveness of performing squat exercises at various angles to show the maximum muscle activity of the Vastus Medialis Oblique (VMO) and Biceps femoris (BF).

Design: Cross-sectional study.

Methods: A total of seventeen healthy young adults ( 8 males and 9 females) voluntarily participated in the study. All subjects randomly performed three different squat variations as follows: A squat performed with the ankle joint at $0^{\circ}$ of incline, a squat performed with the ankle joint at $5^{\circ}$ of incline, and a squat performed with the ankle joint at $10^{\circ}$ incline. Muscle activity was measured using surface electromyography. Electrodes were placed on the VMO and BF to measure the muscle activity on the various ankle angles for comparison analysis.
\end{abstract}

Results: There was a significant increase in bilateral VMO muscle activation at $10^{\circ}$ of incline compared to $0^{\circ}$ and $5^{\circ}(p<0.05)$. Greater increases in muscle activation and exercise effect was observed with increasing incline angles of the board. Changes in bilateral BF muscle activity were found; however, none were found to be significant.

Conclusions: Bilateral VMO activity was found to be significant when the squats were performed at an ankle angle of $10^{\circ}$ of incline when compared to at an ankle angle of $0^{\circ}$ and $5^{\circ}$ of incline. Squats performed on an incline can be recommended as an effective method to facilitate lower extremity muscle activities.

Key Words: Electromyography, Incline, Squat, VMO

\section{Introduction}

Modern society has led a convenient and enriching life through the development of science and technology, however a lack of physical activity due to sedentary lifestyles is related to obesity [1] and related to various adult diseases. Many people in today's society are turning to a fitness center to solve their lack of exercise in a convenient way, and weight training is one of the easiest methods to increase fitness. Weight training has been associated with increased muscle strength, increased bone mass, hypertrophy of connective tissues, and decreased back pain, injury to the joints, and fractures [2]. Weight training is the most effective tool for improving muscle strength. It not only improves muscular strength, muscular power, muscular hypertrophy, and specific muscle endurance, but also improves adaptation, balance, and coordination of the nervous system and improves body fat content with dramatic effect [3].

The lower body exercises of weight training are used in many ways such as calf raise, leg adduction, leg press, and squat exercise. Among these, the squat is the most important and fundamental exercise for lower body training as well as strengthening the bone density, ligaments, and tendons as well as training the important muscles for running, jumping, and lifting. The squat exercise is the most representative exercise for effective muscle development because it is an ex-

Received: 28, February, 2017 Revised: 16 March, 2017 Accepted: 16 March, 2017

Corresponding author: Matthew Choi

Department of Physical Therapy, College of Health Science and Social Welfare, Sahmyook University, 815 Hwarang-ro, Nowon-gu, Seoul 01795, Republic of Korea Tel: 82-2-3399-1863 Fax: 82-2-3399-1639 E-mail: Mdchoidpt@gmail.com

(c) This is an Open-Access article distributed under the terms of the Creative Commons Attribution Non-Commercial License (http://creativecommons.org/licens es/by-nc/4.0) which permits unrestricted non-commercial use, distribution, and reproduction in any medium, provided the original work is properly cited.

Copyright $@ 2017$ Korean Academy of Physical Therapy Rehabilitation Science 
ercise using the upper body muscle as well as the lower body [4,5]. In addition, Vianna et al. [6] reported that the half-squat exercise was significantly higher in energy expenditure than the other exercises such as bench press, triceps extension, and lat pull down.

Squat movement is a good example of closed-chain movement, which simultaneously induces ankle flexion, knee joint, and hip flexion, and it is reported that stress on the anterior cruciate ligament is minimized by reducing shear force of the tibia through joint compression [7].

Closed chain movement efficiently stimulates the internal structures of the joints and specific mechanical receptors around the open chain movement and increases the stability of the joints, creating load axes during weight bearing. Because most of the closed chain movement is performed in the weight-bearing posture, it promotes co-contraction of the main and antagonistic muscles and promotes dynamic stability [8]. It is reported that the typical exercise of a closed chain movement is the squat movement, which not only improves the function in daily life, but also improves the athlete's records and prevents injuries [9].

Kongsgaard et al. [10] reported an increase in muscle activity of the knee extensor muscle during a squat when the ankle joint angle was increased to $25^{\circ}$ compared to doing a squat with the ankle joint angle at neutral. A gradual increase of the ankle joint is helpful for rehabilitation of the knee joint in training of athletes [11]. In the squat movement, when the upper body is leaned forward, it was found that the muscle activity of the erector spinae, gluteus maximus, and biceps femoris (BF) increased [12]. Also Marchetti et al. [13] reported that the quadriceps muscle activity of during a squat was the highest at the knee angle of $90^{\circ}$. The squat movement consists of co-contraction of the quadriceps and the hamstrings muscles [14] and is a movement that strengthens the femoral muscle through eccentric and concentric contraction.

Research on the squat has been actively conducted on the angle of each joint. Studies on muscle activity according to ankle angle have only been carried out to reduce the ankle angle, however, research on the activity of muscle of the femur has not yet been carried out. Therefore, in this study, we investigated the changes of muscle activity of the $\mathrm{BF}$, which is most directly influenced by squat movement according to the change of ankle angle during squat exercise, and which affect knee joint lesion. And an effective squat movement from the physical therapy point of view will help prevent knee joint damage.
Table 1. General characteristics of the subjects $(\mathrm{N}=17)$

\begin{tabular}{lc}
\hline Characteristic & Subject \\
\hline Sex & \\
Male & 8 \\
Female & 9 \\
Age $(\mathrm{yr})$ & $21.58(2.64)$ \\
Height $(\mathrm{cm})$ & $167.35(8.10)$ \\
Weight $(\mathrm{kg})$ & $62.82(11.87)$ \\
\hline
\end{tabular}

Values are presented as number only or mean (SD).

\section{Methods}

\section{Subjects}

This study is aimed at college students who understand and want to participate in the study actively enrolled in Sahmyook University. Seventeen total subjects who signed consents were randomly selected to each group. Eight men and nine women, who did not exercise in extreme a week before the experiment were included. The exclusion criteria are those who have been diagnosed with back pain and prior medical history of lower limb injury, musculoskeletal injuries, and those who have been medically diagnosed where exercising can cause damage. All subjects were instructed not to drink alcohol and/or caffeine on the day before and on the day of the experiment. They were all selected as subjects with no other chronic diseases or diseases related to the muscles to be measured (vastus medialis oblique [VMO], BF) or significant features (Table 1).

\section{Procedures}

The maximum voluntary isometric contraction (MVIC) was measured after the electrodes were attached to the VMO and the BF of the subject. Before the experiment, the researchers gave sufficient explanation about the squat movement to the subjects and the subjects were able to understand the experimental method by pre-practicing each posture at least 3 times. The squat postures were as follows, repeated three times each in a random order.

\section{General squat: neutral ankle angle}

With the feet flat, the feet are spread out shoulder width, and in the erect posture, the arm is extended to the height of the shoulder and held at shoulder width. The arms are stretched forward in movement parallel with the floor, and the waist and knee are bent so that the head and knee do not cross the toes while bending the knees up to $95^{\circ}$ in flexion 


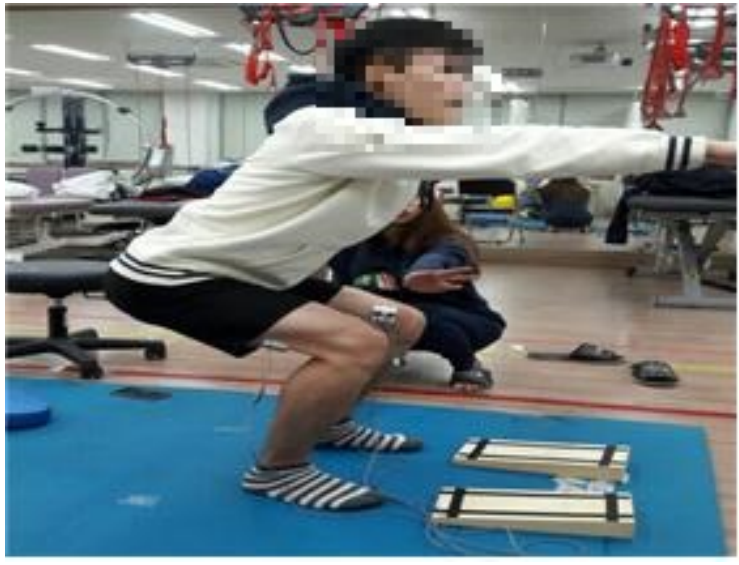

Figure 1. General squat exercise.

\section{[15] (Figure 1).}

\section{Incline $5^{\circ}$ ankle angle}

While standing on an incline wedge of $5^{\circ}$, the feet are spread out shoulder width, and in the erect posture, the arm is extended to the height of the shoulder and held at shoulder width. The arms are stretched forward in movement parallel with the floor, and the waist and knee are bent so that the head and knee do not cross the toes while bending the knees up to $95^{\circ}$ in flexion (Figure 2).

\section{Inline $10^{\circ}$ ankle angle}

While standing on an incline wedge of $10^{\circ}$, the feet are spread out shoulder width, and in the erect posture, the arm is extended to the height of the shoulder and held at shoulder width. The arms are stretched forward in movement parallel with the floor, and the waist and knee are bent so that the head and knee do not cross the toes while bending the knees up to $95^{\circ}$ in flexion (Figure 3).

\section{Procedures}

All subjects were instructed to keep the knee flexed to $95^{\circ}$ for 5 seconds after the knee flexed.

Each condition was repeated three times and the subjects were allowed to take one minute rest between conditions. The experiment was carried out in random order.

To assess muscle activity during the squat exercise, the TeleMyo 2400 G2 Telemetry electromyography (EMG) system (Noraxon Inc., Scottsdale, AZ, USA) was used. The sampling rate of the EMG signal was set to $100 \mathrm{~Hz}$ and the frequency bandwidth was set to $10 \mathrm{to} 450 \mathrm{~Hz}$. The electrodes were attached to the medial fascia at $2 \mathrm{~cm}$ in the medial $60^{\circ}$

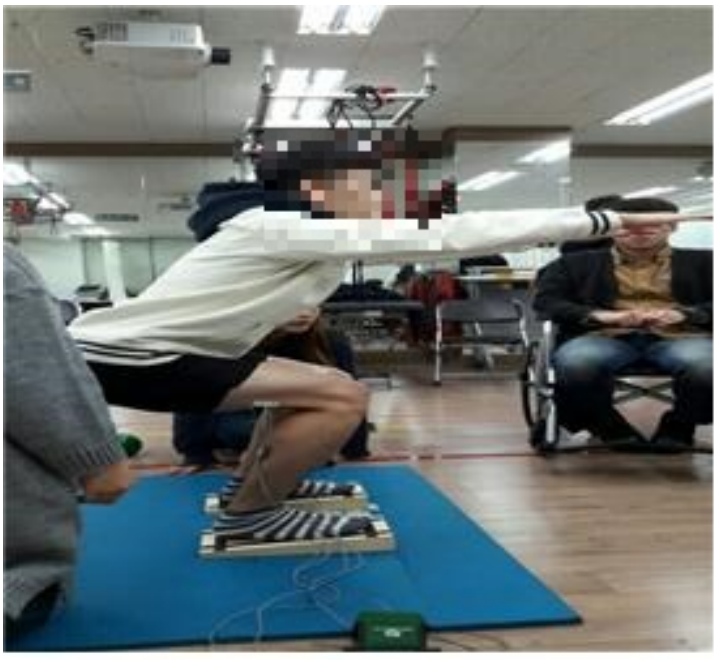

Figure 2. $5^{\circ}$ incline board squat.

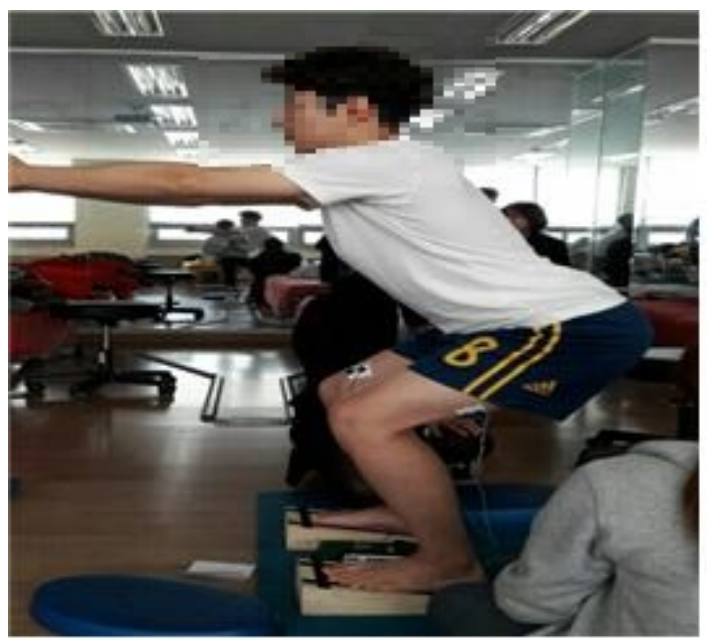

Figure 3. $10^{\circ}$ incline board squat.

diagonal direction from the knee and at the femoral biceps 5 $\mathrm{cm}$ above the medial side of the knee [14].

Before the experiment, MVIC was measured and the contraction values of $\mathrm{BF}$ and medial fascia were obtained for 5 seconds. The BF was examined by the therapist fixing the thighs and lifting the legs in the lying down position, and the medial femoralis was examined by fixing the thigh in the sitting position and lifting the leg forward [15].

\section{Data and statistical analysis}

Muscle EMG signals measured in this study were processed by full wave rectification using the MyoResearch XP Master Edition 1.07 XP software (Noraxon Inc.), and we used the method of dividing by MVIC value and using 
$\% \mathrm{MVC}$ value converted by percentage for the root mean square. For each condition, the knee was flexed and the knee angle was measured at $95^{\circ}$ for 5 seconds [16]. After repeated measurements of three times under all conditions, the mean value was normalized to the MVIC value.

The collected data was analyzed using PASW Statistics ver. 19.0 (IBM Co., Armonk, NY, USA). The general characteristics of the subjects were analyzed by descriptive statistics, and one-way repeated measures analysis of variance was performed to examine the effect of muscle activity on the trunk and lower limb. The least significant difference was used for the post-test to see if there was any difference in the body and leg muscle activity between the different ankle angle posture conditions. All data were statistically significant $(p<0.05)$.

\section{Results}

Comparison of intrinsic light muscle activity of squat posture with angle of incline

Bilateral VMO activity of the squat at $10^{\circ}$ of incline was significantly larger than that of the squat performed at the normal squat and incline $5^{\circ}(p<0.05)$. There was no difference between the bilateral VMO activity of the squat in the incline 5 and the activity of the general squat (Table 2, Figures 4, 5).

\section{Comparison of squat posture activity of biceps muscle with angle of incline}

The activity of the BF muscle in the squat performed at $10^{\circ}$ incline increased from that of the squat performed at the normal squat and the incline $5^{\circ}$, but was not statistically significant. There was no difference in the activity of the quadriceps femoris muscle during a squat performed at $5^{\circ}$ of incline (Table 2, Figures 6, 7).

\section{Discussion}

The purpose of this study was to compare the muscle activity of the VMO and the BF using EMG in order to investigate the effect of the ankle joint changes on the muscle activity of the femoral head.

Table 2. Comparison of activities of lower extremity muscle in squat exercise

$(\mathrm{N}=17)$

\begin{tabular}{|c|c|c|c|c|}
\hline & \multicolumn{2}{|c|}{ Vastus medialis olique } & \multicolumn{2}{|c|}{ Biceps femoris } \\
\hline & Right side & Left side & Right side & Left side \\
\hline GSE (\%MVIC) & $45.83(21.27)$ & $50.55(23.37)$ & $23.90(27.77)$ & $25.75(28.86)$ \\
\hline 5SE (\%MVIC) & $45.08(22.38)$ & $50.14(2168)$ & $23.51(26.45)$ & $26.18(29.39)$ \\
\hline 10SE (\%MVIC) & $61.42(24.63)^{\mathrm{a}, \mathrm{b}}$ & $64.79(20.53)^{\mathrm{a}, \mathrm{b}}$ & $35.35(25.22)$ & $36.38(27.60)$ \\
\hline $\mathrm{F}(p)$ & $11.73(0.01)$ & $10.12(0.00)$ & $3.24(0.68)$ & $3.01(0.80)$ \\
\hline
\end{tabular}

Values are presented as mean (SD).

GSE: general squat exercise, 5SE: squat exercise on the $5^{\circ}$ incline board, 10SE: squat exercise on the $10^{\circ}$ incline board.

${ }^{\mathrm{a}}$ Statistically significant difference with GSE $(p<0.05)$, ${ }^{\mathrm{b}}$ Statistically significant difference with $5 \operatorname{SE}(p<0.05)$.

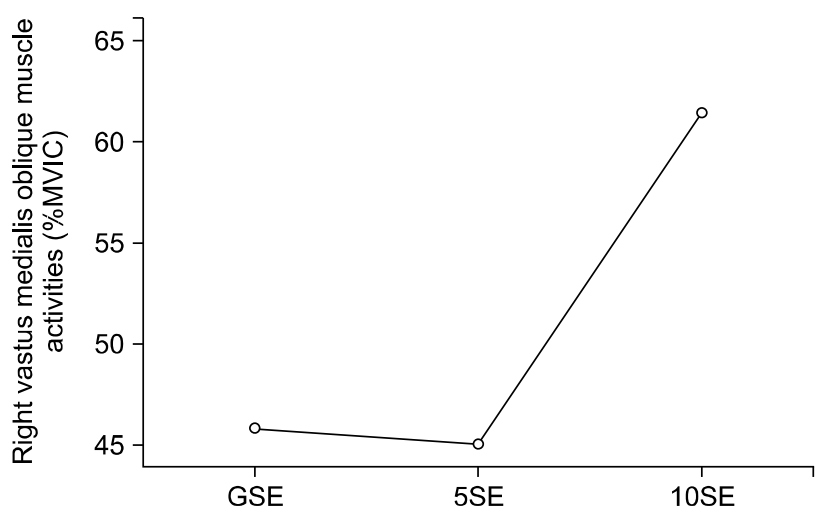

Figure 4. Right vastus medialis oblique muscle activities. GSE: general squat exercise, 5SE: squat exercise on the $5^{\circ}$ incline board, 10SE: squat exercise on the $10^{\circ}$ incline board.

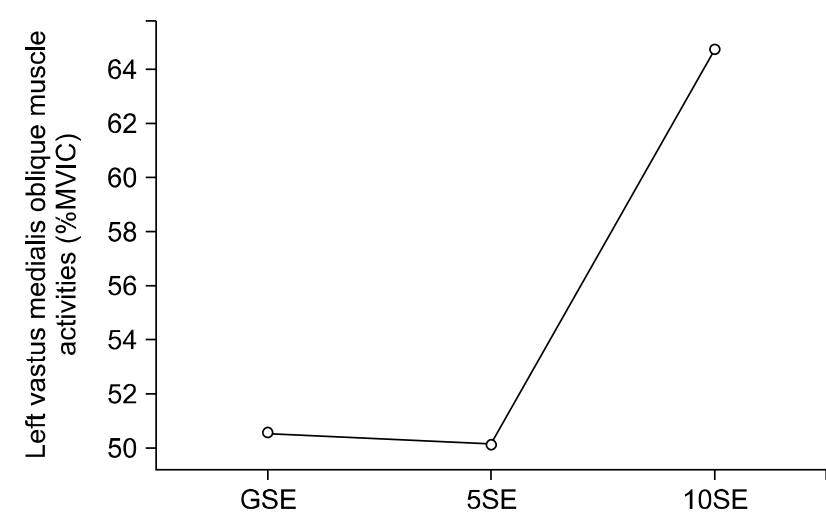

Figure 5. Left vastus medialis oblique muscle activities. GSE: general squat exercise, 5SE: squat exercise on the $5^{\circ}$ incline board, 10SE: squat exercise on the $10^{\circ}$ incline board. 


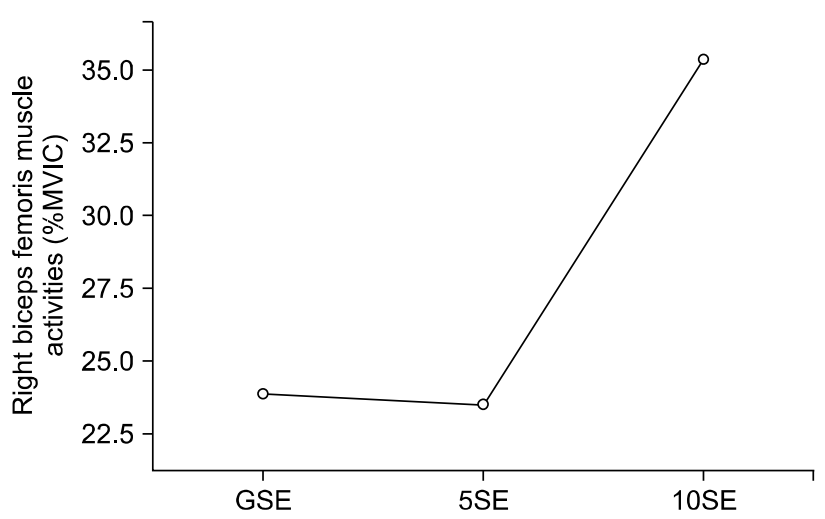

Figure 6. Right biceps femoris muscle activities. GSE: general squat exercise, 5SE: squat exercise on the $5^{\circ}$ incline board, 10SE: squat exercise on the $10^{\circ}$ incline board.

The movement of the squat has been reported to cause simultaneous movement of the ankle joint, knee, and hip joint $[17,18]$, and different muscle activity depending on the angle of flexion of the knee joint [19]. In addition, the body angle increases with increasing instability [20]. The squat movement on the unstable support surface improves the balance of core muscles and enhances the function of the joints and increases the muscle activity of the lower extremity muscles [15].

In the present study, it was found that a squat at $10^{\circ}$ of incline angle at the ankle joint increased the muscle activity of the VMO more than that of the squat performed at neutral or the squat performed at $5^{\circ}$ of incline angle at the ankle joint. The BF muscle activity increased, but no significant difference was found. This is due to the instability due to the movement and reduction of the base of support during the squat movement as the angle of the base plane increases, and the muscle activity of the VMO muscle is increased to overcome this [21]. In addition, increasing the ankle angle causes co-contraction of the muscles to maintain balance due to the instability of the support surface, resulting in muscle contraction of the BF to overcome instability [22]. In addition, Spanu and Hefzy [14] studied the ankle joint angle at $20^{\circ}$. The incline at $10^{\circ}$ limited the ankle dorsiflexion to $50 \%$, resulting in instability of the ankle, and co-contraction of the muscles. To overcome instability, the biceps muscle activity increased [23].

The squat movement is a complex exercise in which not only the femoral muscle, but also the whole muscles of the trunk and lower limbs. An incline of $10^{\circ}$ reduced the movement of the ankle joint by narrowing the support surface, thereby limiting muscle activity of the calf muscles during

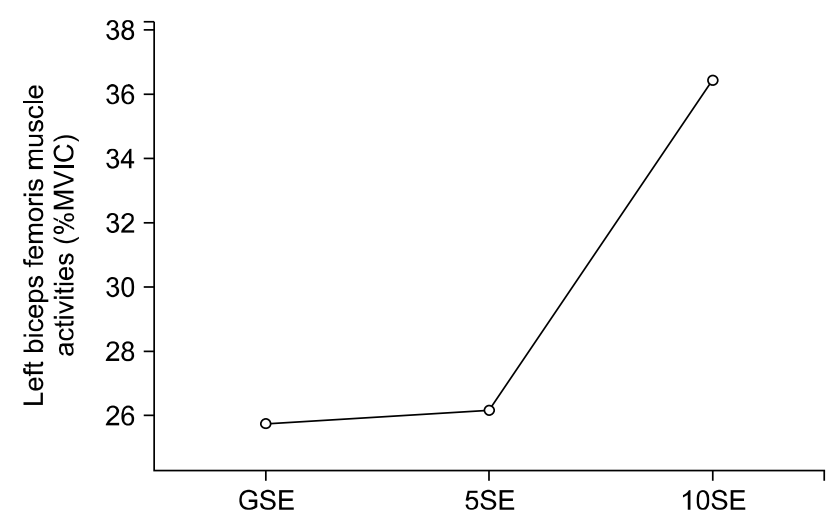

Figure 7. Left biceps femoris muscle activities. GSE: general squat exercise, 5SE: squat exercise on the $5^{\circ}$ incline board, 10SE: squat exercise on the $10^{\circ}$ incline board.

the squat exercise, thus substituting the knee joint, which increased the muscle activity of the medial lateral muscles.

In this study, it was confirmed that the squat movement at $10^{\circ}$ of incline significantly increased the muscle activity of the $\mathrm{BF}$ than the squat at neutral or at $5^{\circ}$ of incline. It is considered that the increase of the base angle causes the limitation of the movement of the ankle joint, which causes the center of gravity to move backward and this also causes the increase of the muscle activity of the medial side.

$\mathrm{Na}$ [24] confirmed the muscle activity of the lower limb according to the position of the foot during squat exercise, but the activity of the inner and outer muscles was high in the toe-in and toe-out position. This is thought to be due to the reduction of the base plane of the sagittal plane. As a result, the squat performed at an increase of the angle of the base plane can provide an efficient squat movement suitable for the subject.

In this study, the number of subjects is small and normal healthy adults are targeted. There are limits to the fact that only two muscles of the femur are analyzed and other muscles of the trunk and lower limbs are not identified. Therefore, in future studies, it would be necessary to study the muscle activity of the trunk muscle and various muscles in consideration of these limitations. Through training research rather than a cross-sectional study, muscle strengthening, thickness change and muscle fatigue were evaluated as well as the effects on the lower limbs.

This study demonstrated that the increase in angle of incline in healthy normal adults affects muscle activity of femoral head. This study suggests that this method of intervention can be an effective method of improving the health and strength of the lower limbs of normal and athletes. 


\section{Acknowledgements}

I sincerely thank Prof. Jung for her guidance and encouragement in carry out this study.

\section{Conflict of Interest}

The authors declared no potential conflicts of interest with respect to the authorship and/or publication of this article.

\section{References}

1. Bensimhon DR, Kraus WE, Donhaue MP. Obesity and physical activity: a review. Am Heart J 2006;151:598-603.

2. Suzuki M. Dumbbell exercise and health. Paper presented at: The 1st International Symposium on Dumbbell Exercise; 1996. p. 1-5.

3. Kraemer WJ, Ratamess NA, French DN. Resistance training for health and performance. Curr Sports Med Rep 2002;1:165-71.

4. Escamilla RF. Knee biomechanics of the dynamic squat exercise. Med Sci Sports Exerc 2001;33:127-41.

5. Goldberg L, Elliot DL, Kuehl KS. A comparison of the cardiovascular effects of running and weight training. J Strength Cond Res 1994;8:219-24.

6. Vianna JM, Lima JP, Saavedra FJ, Reis VM. Aerobic and anaerobic energy during resistance exercise at $80 \%$ 1RM. J Hum Kinet 2011;29A:69-74

7. Palmitier RA, An KN, Scott SG, Chao EY. Kinetic chain exercise in knee rehabilitation. Sports Med 1991;11:402-13.

8. Kisner C, Colby L. Therapeutic exercise: foundation \& techniques. 5th ed. Philadelphia: F.A. Davis Company; 2007. p. 728-54.

9. Cappozzo A, Felici F, Figura F, Gazzani F. Lumbar spine loading during half-squat exercises. Med Sci Sports Exerc 1985;17:613-20.

10. Kongsgaard M, Aagaard P, Roikjaer S, Olsen D, Jensen M, Langberg $\mathrm{H}$, et al. Decline eccentric squats increases patellar tendon loading compared to standard eccentric squats. Clin Biomech (Bristol, Avon) 2006;21:748-54.

11. Richards J, Selfe J, Sinclair J, May K, Thomas G. The effect of different decline angles on the biomechanics of double limb squats and the implications to clinical and training practice. $\mathrm{J}$ Hum Kinet 2016;52:125-38.

12. Lee TS, Song MY, Kwon YJ. Activation of back and lower limb muscles during squat exercises with different trunk flexion. J Phys Ther Sci 2016;28:3407-10.

13. Marchetti PH, Jarbas da Silva J, Jon Schoenfeld B, Nardi PS, Pecoraro SL, D'Andréa Greve JM, et al. Muscle activation differs between three different knee joint-angle positions during a maximal isometric back squat exercise. J Sports Med (Hindawi Publ Corp) 2016;2016:3846123.

14. Spanu CE, Hefzy MS. Biomechanics of the knee joint in deep flexion: a prelude to a total knee replacement that allows for maximum flexion. Technol Health Care 2003;11:161-81.

15. Isear JA Jr, Erickson JC, Worrell TW. EMG analysis of lower extremity muscle recruitment patterns during an unloaded squat. Med Sci Sports Exerc 1997;29:532-9.

16. Criswell E. Cram's introduction to surface electromyography. Burlington: Jones \& Bartlett Learning; 2010.

17. Kendall FP, McCreary EK, Provance PG, Rodgers MM, Romani WA. Muscles: testing and function with posture and pain. 5 th ed. Baltimore: Lippincott Williams \& Wilkins; 2005.

18. Stevens VK, Coorevits PL, Bouche KG, Mahieu NN, Vanderstraeten GG, Danneels LA. The influence of specific training on trunk muscle recruitment patterns in healthy subjects during stabilization exercises. Man Ther 2007;12:271-9.

19. Donatelli RA. Abnormal biomechanics of the foot and ankle. J Orthop Sports Phys Ther 1987;9:11-6.

20. McGinty G, Irrgang JJ, Pezzullo D. Biomechanical considerations for rehabilitation of knee. Clin Biomech (Bristol, Avon) 2000;15:160-6.

21. Hamill J, Knutzen K. Biomechanical basis of human movement. 2nd ed. Philadelphia: Lippincott Williams \& Wilkins; 2003.

22. Saeterbakken AH, Fimland MS. Muscle force output and electromyographic activity in squats with various unstable surfaces. J Strength Cond Res 2013;27:130-6.

23. Shumway-Cook A, Woollacott M. Normal postural control. Motor control: translation research into clinical practice. Philadelphia: Lippincott Williams \& Wilkins; 2001. p. 158-86.

24. Na YC. Muscle activity analysis of erector spinae and rectus femoris depending on toe out angles in squat movement [Master thesis]. Daejeon: Chungnam National University; 2013. 